\title{
PENGETAHUAN TENTANG DIET DIABETES MELITUS BERPENGARUH TERHADAP KEPATUHAN KLIEN MENJALANI DIET
}

\author{
Dewy Haryanti Parman ${ }^{1}$, Hadriana ${ }^{2}$ \\ 1.Fakultas Ilmu Kesehatan Universitas Borneo Tarakan, \\ 2. RSUD Mantri Raga Kota Tarakan. \\ *Email: dewyanmarsya79@gmail.com
}

\begin{abstract}
Abstrak
Data dari RSU DR. Wahidin Sudirohusodo selama setahun, pasien yang menderita Diabetes Melitus sebanyak 709 orang, yang terdiri dari laki-laki 346 orang, perempuan 363 orang, dan dari data klasifikasi DM, yang luka dibetik sebanyak 71 orang, yang terjadi karena salah satu penyebabnya ketidakpatuhan menjalankan dietnya, banyaknya kasus komplikasi pada DM, sehingga peneliti tertarik melakukan penelitian tentang hubungan tingkat pengetahuan tentang diet DM dengan kepatuhan klien menjalani diet. Tujuan dari penelitian ini adalah mendapatkan gambaran hubungan tingkat pengetahuan tentang diet DM dengan kepatuhan klien menjalani diet di ruang poliklinik Endokrin RSUP DR. Wahidin Sudirohusodo.Dalam penelitian ini peneliti menggunakan desain penelitian analitik dengan menggunakan metode cross sectional, Populasi adalah semua pasien DM yang datang berobat ke Poliklinik Endokrin. Sampel penelitian menggunakan tehnik Purposive Sampling, Instrumen (alat pengumpul data) yang digunakan adalah kuisioner, analisa yang digunakan pada penelitian ini menggunakan analisis univariat dan bivariat dengan menggunakan uji kai-kuadrat. Hasil dari uhi X2 dengan menggunakan SPSS diperoleh hasil nilai X2 lebih besar dari nilai X2 tabel 0,05, sehingga ada hubungan tingkat pengetahuan tentang diet DM dengan kepatuhan klien menjalani diet, dan nilai $\mathrm{P}$ lebih kecil dari intervalnya makin bermakna suatu penelitian. Dan dari nilai odds ratio $(7,250)$ 7,250 kali lebih besar untuk patuh menjalani diet. Kesimpulan: menggambarkan bahwa responden yang berpengetahuan cukup sama besar dengan yang berpengetahuan kurang dan kepatuhan terhadap diet lebih besar dibandingkan dengan yang tidak patuh serta ada hubungan antara tingkat pengetahuan tentang diet Diabetes Melitus dengan kepatuhan klien menjalani diet di Ruang Poliklinik Endokrin RSUP Dr. Wahidin Sudirohusodo Makassar.
\end{abstract}

Kata kunci: Tingkat pengetahuan, Diabetes mellitus, Diet.

\begin{abstract}
Knowledge About Diet Diabetes Melitus Influence to The Compliance Clients Walking Diet. Data from RSU DR. Wahidin Sudirohusodo for a year, patients suffering from Diabetes Mellitus as many as 709 people, consisting of 346 men, 363 women, and from the classification data DM, which injured 71 people, which occurred due to one cause of non-compliance to run his diet, the number of cases of complications in DM, so researchers interested in conducting research on the relationship of knowledge level about DM diet with client compliance through diet. The purpose of this study is to get a picture of the relationship of knowledge level about DM diet with client compliance to diet in the endocrine polyclinic room RSUP DR. Wahidin Sudirohusodo.In this study researchers used the design of analytical research using cross sectional method, the population is all DM patients who come to the Endocrine Polyclinic treatment. The sample of research using technique of Purposive Sampling, Instrument (data collecting instrument) used is questionnaire, the analysis used in this research using univariate and bivariate analysis by using kai-square test. Result from test X2 by using SPSS obtained result X value greater than the value of X2 table 0.05 , so there is a relationship of knowledge level about DM diet with client compliance to diet, and $\mathrm{P}$ value smaller than interval more meaningful a research. And from the value of odds ratio (7,250) 7,250 times greater to adhere to diet. Conclusion illustrates that the respondents who are knowledgeable enough equal to those with less knowledge and adherence to the diet is greater than the non-adherence and there is a relationship between the level of knowledge about Diabetes diet Miletus with the compliance of clients undergoing diet at the Endocrine Polyclinic Room of Dr. Wahidin Sudirohusodo Makassar.
\end{abstract}

Keywords: level of knowledge, diabetes mellitus, diet. 


\section{Pendahuluan}

Penyakit DM atau yang lebih dikenal di masyarakat dengan penyakit gula merupakan salah satu penyakit yang perlu mendapatkan perhatian khusus sehingga pasien DM harus mendapat perawatan dan pengelolaan yang baik agar dapat hidup normal dan sehat (Johnson, 1998), hal tersebut merupakan peran penting bagi perawat sebagai tenaga kesehatan. Indonesia adalah salah satu negara berkembang mengalami peningkatan juga pada jumlah penyandang diabetisi. World Health Organization (WHO) melaporkan bahwa pada tahun 2030 jumlah penyandang diabetes di Indonesia akan berjumlah 21.3 juta orang, menempati urutan keempat setelah Amerika Serikat, Cina dan India dalam jumlah penyandang DM terbanyak (Perkumpulan Endokrinologi Indonesia/PERKENI, 2011). Survey yang dilakukan oleh Badan Pusat Statistik (BPS) melaporkan pada tahun 2003 jumlah penyandang diabetes adalah 13.7 juta, berdasarkan pola pertambahan penduduk diperkirakan tahun 2030 akan menjadi 20.1 juta dengan tingkat prevalensi $14.7 \%$ untuk daerah urban serta $7.2 \%$ untuk daerah rural (PDPERSI, 2011).
Diabetes merupakan penyakit yang tidak dapat disembuhkan, namun dapat dicegah dan dikontrol melalui penatalaksanaan DM yang benar dan tepat sehingga komplikasi akut maupun komplikasi kronik tidak terjadi. Komplikasi DM dapat dikendalikan, dicegah dan dihambat melalui pengendalian kadar glukosa darah yang termasuk dalam lima pilar penatalaksanaan DM. Penatalaksanaan diabetes melibatkan tim pelayanan kesehatan, terdiri dari: dokter, perawat, ahli gizi, ahli farmasi, edukator diabetes, serta melibatkan penyandang diabetes dan keluarga melalui edukasi penatalaksanaan diabetes (Waspadji, Soebekti, Yunir \& Sukardji, 2009).

Diabetes mellitus adalah masalah kesehatan yang diakibatkan oleh proses degenerasi. Dari profil tahun 1999, di Jepang dan Malaysia tahun 1996 Diabetes mellitus menempati urutan ke 10 penyebab kematian, dan dari berbagai penelitian di Indonesia didapatkan angka prevalensi penyakit DM 1,5 \% - 2,3 \% pada penduduk usia diatas 15 tahun. (Fan\&Sidani, 2009). Diperkirakan pola pertambahan penduduk tahun 2010 ada 178 juta penduduk berusia diatas 20 tahun dan dengan asumsi prevalensi DM sebesar 2 \% akan didapatkan 3,56 juta penderita 
DM di Indonesia. (Jurnal Kedokteran Indonesia, 2003). Proporsi penyakit Diabetes mellitus di Sulawesi Selatan pada tahun 1996 sebesar 1,61\%, pada tahun 1997 sebesar 1,62 \%, dan pada tahun 1998 sebesar $11,5 \%$. Kasus baru DM pada pasien rawat inap untuk kelompok umur >59 tahun sebesar $14,83 \%$, dan proporsi kematian DM pada pasien rawat inap sebesar $4,7 \%$.

Berdasarkan data yang didapatkan dari RSUP DR. Wahidin Sudirohusodo, mulai Januari 2003 sampai dengan Desember 2003, pasien yang menderita Diabetes mellitus sebanyak 709 orang, yang terdiri dari laki-laki sebanyak 346 orang dan perempuan 363 orang. Adapun pelayanan kesehatan yang diberikan pada pasien DM berupa perawatan yang bertujuan dalam jangka pendek adalah menghilangkan keluhan dan gejala yang dirasakan pasien, sedang jangka panjang untuk mencegah komplikasi, dimana salah satu perawatan yang terpenting adalah perencanaan diet pada pasien, dan keberhasilan perencanaan tersebut diperlukan kesadaran pada penderita DM akan dietnya yang tertujuan untuk mempertahankan kadar glukosa darah dalam batas normal.

Diet merupakan salah satu pilar utama perawatan DM yang memerlukan waktu cukup lama dan kecermatan dalam pelaksanaannya baik dari pasien sendiri maupun dari lingkungannya seperti keluarga, untuk memperoleh hasil yang optimal, seorang pasien DM harus mampu mengendalikan diri selama melaksanakan program diet (Leslie, 1998) dan pasien harus makan dalam porsi yang terbatas sehingga perlu perencanaan dalam pemilihan menu agar dapat melaksanakan diet dan pasien tersebut tidak merasa bosan. Dengan mengikuti perawatan yang benar maka diharapkan pasien DM mampu hidup secara normal, tapi bila pasien DM tidak memperhatikan pelaksanaan diet tersebut maka akan mengakibatkan komplikasi sampai dengan meninggal dunia.

Dengan melihat data tersebut diatas dapat diketahui betapa pentingnya kepatuhan menjalankan diet sehingga peneliti tertarik untuk meneliti kasus tentang "apakah tingkat pengetahuan tentang diet DM memiliki hubungan dengan kepatuhan klien menjalani diet di ruang poliklinik endokrin RSUP DR. Wahidin Sudirohuso?

\section{Metode}

Penelitian ini menggunakan desain penelitian analitik dengan menggunakan 
metode cross sectional. Populasi dalam penelitian ini adalah semua pasien DM yang sedang memeriksakan diri di poliklinik endokrin RSUP DR. Wahidin Sudirohusodo, dan besarnya populasi disesuaikan dengan jumlah pasien yang datang berobat. Teknik pengambilan sampel dengan Purpose Sampling yaitu mengambil sampel target mencapai 70 orang yang sedang memeriksakan diri. Sampel ini didapatkan $10 \%$ dari jumlah populasi 709 orang di poliklinik endokrin RSUP DR. Wahidin Sudirohusodo. Kriteria Inkulsi: Pasien yang sedang melakukan diet, dalam kedaan sadar, dapat membaca dan menulis dan mau berpartisipasi aktif dalam penelitian ini.

\section{Hasil}

Pengumpulan data dalam penelitian ini dilakukan di tuang Poliklinik Endokrin RSUP DR. Wahidin Suirohusodo Makassar dari tanggal 5 sampai 16 Maret 2004. Besar sampel yang diteliti sebanyak 70 responden di uji dengan menggunakan analisis univariat dan analisis bivariat, sebagai berikut:
Instrumen (alat pengumpulan data) yang digunakan dalam penelitian ini adalah angket atau kuisioner yang di modifikasi dengan mengacu pada konsep dan teori yang dihubungkan dengan pengetahuan responden tentang diet DM dan kepatuhan responden melakukan diet. Uji hipotesis dengan mengunakan Analisis Bivariat Untuk melihat hubungan dari tiap variabel independen yang meliputi pengetahuan tentang diet DM, dan variabel dependen yaitu kepatuhan klien menjalani diet, maka digunakan uji statistik kai kuadrat. Hasil data yang didapat dimasukkan komputer dalam program SPSS versi 11.5. 


\section{Analisis Univariat}

Tabel. 1 Distribusi Frekuensi Responden Berdasarkan Jenis Kelamin, Tingkat Pendidikan dan Umur di Ruang Poliklinik Endokrin RSUP Dr. Wahidin Sudirohusodo Makassar Maret 2004

\begin{tabular}{ccc}
\hline Karakteristik & Jumlah & Presentasi \\
\hline Jenis Kelamin & 36 & 51,4 \\
Laki - laki & 34 & 48,6 \\
Perempuan & 70 & 100.00 \\
Total & & \\
Tingkat Pendidikan & 4 & 5,7 \\
TidakTamat SD & 13 & 18,6 \\
Tamat SD & 9 & 12,9 \\
Tamat SMP & 26 & 37,1 \\
Tamat SMA & 18 & 25,7 \\
Tamat P.T & 70 & 100.00 \\
Total & & \\
U s i a & 64 & 91,4 \\
$\leq 65$ & 6 & 8,6 \\
$>65$ & 70 & 100.00 \\
Total & &
\end{tabular}

Sumber : Data primer

Dalam analisa univariat ini akan dibahas hasil distribusi frekuensi seperti yang akan diuraikan dibawah ini: Berdasarkan tabel 1 diatas didapatkan data bahwa dari 70 responden, yang berjenis kelamin laki-laki sebanyak 36 orang $(51,4 \%)$ dan yang berjenis kelamin perempuan sebanyak 34 orang (48, 6\%). Sedangkan berdasarkan tingkat pendidikan didapatkan hasil yang tidak tamat SD sebanyak 4 orang $(5,7 \%)$, tamat SD sebanyak 13 orang $(18,6 \%)$, tamat SMP sebanyak 9 orang (12, 9\%), tamat SMA sebanyak 26 orang $(37,1 \%)$, dan Perguruan Tinggi sebanyak 18 orang $(25,7 \%)$, kemudian kriteria responden berdasarkan umur yaitu berusia $\leq 65$ tahun sebanyak 64 orang $(91,4 \%),>65$ tahun sebanyak 6 orang $(8,6 \%)$.

Tabel. 2 Distribusi Frekuensi Responden Berdasarkan Tingkat Pengetahuan Klien Tentang Diet Diabetes Melitus di Ruang Poliklinik Endokrin di RSUP Dr. Wahidin Sudirohusodo Makassar

\begin{tabular}{ccc}
\hline Tingkat Pengetahuan & Frekuensi & $\%$ \\
\hline Kurang & 35 & 50,0 \\
Cukup & 35 & 50,0 \\
\hline Total & 70 & 100,00 \\
\hline
\end{tabular}

Sumber: Data primer 
Berdasarkan tabel 2 diatas, didapatkan data bahwa dari 70 responden memiliki tingkat pengetahuan cukup sebanyak 35 orang $(50,0 \%)$ dan sebagian responden memiliki tingkat pengetahuan kurang sebanyak 35 orang $(50,0 \%)$.

Tabel. 3 Distribusi Frekuensi Responden Berdasarkan Kepatuhan Klien Menjalani Diet Diabetes Melitus Ruang Poliklinik Endokrin di RSUP Dr. Wahidin Sudirohusodo Makassar

\begin{tabular}{ccc}
\hline Kepatuhan & Frekuensi & \% \\
\hline Tidak Patuh & 27 & 38,6 \\
Patuh & 43 & 61,4 \\
\hline Total & 70 & 100,00 \\
\hline Sumber $:$ Data primer & &
\end{tabular}

Berdasarkan tabel 3 diatas, didapatkan data bahwa dari 70 responden, sebagian besar responden memiliki kepatuhan menjalani diet Diabetes Melitus

\section{Analisis Bivariat}

Analisis bivariat ini dilakukan dengan maksud untuk mempelajari hubungan antar variabel, yaitu tingkat pengetahuan tentang diet Diabetes sebanyak 43 orang $(61,4 \%)$ dan sebagian kecil tidak patuh menjalani diet Diabetes Melitus sebanyak 27 orang $(38,6 \%)$.

Melitus dan kepatuhan klien menjalani diet menggunakan uji statistic KiKuadrat, seperti yang tertera dibawah ini:

Tabel. 4 Hasil Analisis Hubungan Tingkat Pengetahuan Tentang Diet Diabetes Melitus dan Kepatuhan Klien Menjalani Diet di Ruang Poliklinik Endokrin di RSUP Dr. Wahidin Sudirohusodo Makassar

\begin{tabular}{|c|c|c|c|c|c|c|}
\hline \multirow[b]{2}{*}{ Kepatuhan } & \multicolumn{6}{|c|}{ Total } \\
\hline & $\begin{array}{l}\text { Tidak } \\
\text { patuh }\end{array}$ & Patuh & $X^{2}$ & $P$ & Ratio & Odds \\
\hline Kurang & 21 & 14 & 35 & 13,556 & 0,001 & 7,250 \\
\hline Cukup & 6 & 29 & 35 & & & \\
\hline Total & 27 & 43 & 70 & & & \\
\hline
\end{tabular}

Sumber : Data primer

Berdasarkan tabel 4 dapat dilihat, dari 70 responden dengan menggunakan SPSS versi 11. 5 diperoleh hasil uji statistik kai-kuadrat sebagai berikut: nilai $X^{2}$ hitung $(13,566)>$ dari $X^{2}$ tabel $0,05=(3,481)$, dengan nilai $p$ dibawah $0.05(0.01<p 0,05)$, dari nilai odds ratio 7,250 (95\% Confidence Interval 2. 
392 - 21. 979) menunjukkan bahwa responden yang menunjukkan pengetahuan cukup berpeluang 7, 250 kali lebih besar untuk patuh menjalani diet dari pada responden yang berpengetahuan kurang. Dari analisis tersebut dapat diartikan bahwa ada hubungan antara tingkat pengetahuan tentang diet Diabetes Melitus dengan kepatuhan klien menjalani diet.

\section{Pembahasan}

Hasil analisa univariat menunjukkan bahwa responden yang berpengetahuan cukup sama besar dengan responden yang berpengetahuan kurang. Kemudian untuk kepatuhan klien, lebih besar responden yang patuh daripada klien yang tidak patuh mnjalani diet Diabetes Melitus. Pasien Diabetes Melitus dapat hidup normal asalkan mereka mengetahui dengan baik keadaanya dan cara pelaksanaan penyakit yang dideritanya, mereka dapat belajar tentang cara penyuntukan insulin sendiri, memantau kadar gula darah, dan memanfaatkan informasi untuk mengatur dosis insulin dan merencanakan diet agar dapat mengontrol hiperglikemia dan hipoglikemia (Haddad, Kenny, Wells, 2001). Penderita DM yang diberi konsultasi gizi dengan standard diet disertai petunjuk dan penjelasan yang rinci cara mengaplikasi serta diberikan pengertian dan pemahaman tentang manfaat diet terhadap pemeliharaan kesehatan, dan pasien akan terdorong untuk menerapkan standar diet yang diberikan dalam mengkonsumsi makanan sehari-hari. Diharapkan setelah diberikan pengetahuan tentang pemenuhan gizi standar, pasien akan lebih mengerti dan memahami tentang penyakitnya.

Dari hasil analisa bivariat melalui uji statistik kai-kuadrat diperoleh data hubungan antara tingkat pengetahuan tentang diet Diabetes Melitus dengan kepatuhan klien menjalani diet, dimana $X^{2}$ hitung $(13,566)>$ dari $X^{2}$ tabel $0,05=$ (3, 481), dengan nilai $P$ dibawah 0.05 $(0.01<p 0.05)$ yang berarti penelitian tersebut bermakna sekali karena makin kecil nilai intervalnya makin bermakna suatu penelitian. Demikian pula dari nilai odds ratio $(7,250)$ menunjukkan bahwa responden yang menunjukkan pengetahuan cukup berpeluang 7, 250 kali lebih besar untuk patuh menjalani diet dari pada responden yang berpengetahuan kurang.

Pengetahuan tentang kesehatan dapat membantu individu-individu tersebut untuk beradaptasi dengan penyakitnya, mencegah komplikasi dan 
mematuhi program terapi dan belajar untuk memecahkan masalah ketika menghadapi situasi baru. Sebenarnya penyakit Diabetes Melitus itu sendiri dapat dikendalikan melalui program perencanaan tentang diet secara matang dan cermat.

Kepatuhan jangka panjang terhadap perencanaan makan merupakan salah satu aspek yang paling menimbulkan tantangan dalam pelaksanaan Diabetes Melitus. Bagi pasien obesitas, tindakan membatasi kalori mungkin lebih realistis untuk membantu klien dalam mengikutsertakan kebiasaan diet yang baru kedalam gaya hidupnya maka keikutsertaannya dalam terapi perilaku, dukungan kelompok dan penyuluhan gizi yang berkelanjutan. Tujuan yang paling penting dalam pelaksanaan diet bagi klien Diabetes Melitus adalah pemberian asupan kalori untuk mencapai atau mempertahankan berat badan yang sesuai dan pengendalian kadar glukosa darah. Daftar bahan makanan penukar bagi perencanaan makan harus disampaikan kepada klien dengan penggunaan jumlah kalori yang tepat yang disertai kepatuhan klien terhadap diet. Perawat memegang peranan penting mengkomunikasikan informasi yang tepat kepada ahli diet dan menambah pemahaman klien. Bagi sebagian klien belajar menggunakan system makanan pengganti mungkin sulit dilakukan hal ini dapat berhubungan dengan keterbatasan kemampuan intelektual klien untuk memahami hal tersebut atau dengan persoalan emosional seperti sulit menerima kenyataan bahwa dirinya menderita Diabetes atau perasaan bahwa dirinya disisihkan atau bahwa makanannya kini dibatasi secara tidak adil (Brunner \& Suddarth, 2002).

Diabetes Melitus merupakan penyakit menahun yang umumnya diderita seumur hidup, keberhasilan pengendalian kadar gula darah bukan hanya ditentukan oleh obat oral maupun insulin melainkan ditentukan pula oleh kepatuhan klien terhadap pengaturan makan yang berlaku untuknya, solusi untuk membangkitkan kepatuhan ialah dengan memberikan informasi tentang penyakitnya dan pengaturan makan yang baik untuknya (PERKENI, 2011).

Dari keterpaparan hubungan diatas dapat diartikan bahwa kecenderungan kepatuhan penderita Diabetes Melitus terhadap diet sangat besar hubungannya dengan tingkat pengetahuan klien terhadap diet, terutama mengkomunikasikan informasi yang tepat kepada klien tentang diet 
yang benar melalui pemberian pendidikan kesehatan, serta adanya sikap positif dari klien untuk mematuhi program terapi.

\section{Kesimpulan}

Hasil dari uji univariat menggambarkan bahwa, pasien yang memiliki pengetahuan yang cukup tentang diet DM akan lebih patuh menjalankan dietnya karena sudah mengetahui dampak yang dapat ditimbulkan dari perencanaan diet yang salah melalui pengalaman selama menjadi pasien Diabetes Melitus dan informasi yang didapatkan dari petugas kesehatan. Pasien yang memiliki pengetahuan tentang diet DM sama banyaknya dengan pasien yang berpengetahuan kurang. Kemudian yang patuh menjalankan dietnya lebih besar dari yang tidak patuh yang didapatkan dari hasil analisa bivariat melalui uji kai kuadrat dengan program SPSS versi 11,5 dan diperoleh $\mathrm{x}^{2}$ hitung $(13,566)>$ $\mathrm{x}^{2}$ tabel $0,05=(3,481)$ yang berarti ada hubungan antara tingkat pengetahuan tentang diet Diabetes Melitus dengan kepatuhan klien menjalani diet di Ruang Poliklinik Endokrin RSUP DR. Wahidin Sudirohusodo Makassar.

\section{Keterbatasan Penelitian}

Beberapa keterbatasan yang dirasakan peneliti selama melaksanakan penelitian adalah sebagai berikut: Pengetahuan peneliti tentang metodologi penelitian masih kurang dan penelitian ini merupakan pengalaman meneliti yang pertama, penelitian dilakukan dengan skala kecil dan penelitian ini dilakukan hanya di satu rumah sakit sehingga hasilnya tidak dapat digeneralisasikan.

\section{Referensi}

Aditama, Tjandra. (2009). Prevalensi di Indonesia. Makalah disampaikan dalam seminar memperingati hari diabetes sedunia. Jakarta.

Brunner and Suddarth. (2002). Buku Ajar Keperawatan Medikal Bedah, edisi 8 volume 2. Jakarta: EGC

Boule N.G., Haddad E., Kenny G.P., Wells G.A.,Sigal R.J (2001) Effect of exercise on Glycemic control and Body mass in type 2 Diabetes Mellitus. A metaanalysis of controlled clinical trials. Ameican medical Association. Vol 286. 1218 -1227. Brod, M., Kongso, J.H., Lessard, S., 
Christensen, T.L. (2008).

Psychological Insulin Resistence:

Patient Beliefs and Implications for Diabetes Management. Quality Life Research, 18, 23-32.

Capes, S., Bourgh, S. (2008). Preventing Coronary Artery Disease in People with Diabetes. Canadian Diabetes Association, 21(4), 27-35

Carpenter, Roger D. (2008). Cognitive Appraisal of Perceived Threat of Diabetes and Adherence to Self Manajement Behaviour.

Google.Books. Page 72-75

Castaneda C., Layne J.E., Munoz L., Gordon P.L., Walsmith J., et al.(2002). A randomized controlled trial of resistance Exercise Training to Improve Glycemic control in Older Adults With type 2 Diabetes. Diabetes care.Vol.25.2335-2341.

Everett, Joan. (2007). Insulin initiation in type 2 diabetes: experience and insights. Journal of Diabetes Nursing,11(8), 311-318

Fan L.F.,Sidani,S. (2009). Effectiveness of Diabetes Self Management Education Intervention Elements: A Meta Analysis. Canadian Journal of Diabetes. 33(1), 18-26
Funnel,Martha. (2006). The Diabetes Attitudes, Wishes and Needs (DAWN) Study. Clinical Diabetes, 24(4), 154-155

Funnel,Martha. (2007). Overcoming Barriers to The Initiation of Insulin Therapy. Clinical Diabetes, 25(1), 36-38

Garcia,PinoJ.M., Garcia,RioF.,Diez, J.J., Mendieta, G., Racionero, M., Lobato, S.D., Villamor, J. (1998). Regulation of Breathing in Hyperthyroidism : Relationship to Hormonal and Metabolic Changes. Europe Respiratpry Journal ;12;400-407

Gaglia,J.L.,Wyckoff,J.,

Abrahamson,M.J.(2004). Acute Hyperglicemic Crisis in Elderly. Med.Cli.Nam Journal. 1063-1084 Haque, M., Navsa, M., Emerson, S.H, Dennison, C.R, Levitt, N.S. (2005). Barriers to initiating insulin therapy in patients with type 2 diabetes mellitus in public sector primary health care center in Cape town. Journal of Endocrinology Metabolism and Diabetes of South Africa, 95 (10),798-802

Hermanns, N, Mahr, M., Kulzer ,B., Skovlund, S.E, Haak,T. (2010). Barriers Toward Insulin Tharapy 
in Type 2 Diabetic Patients: Result of an Observational Longitudinal Study. Health and Quality of Life Outcomes, 8(113), $1-6$.

Kirtland, K.A, Li, Y.F, Geiss, L.S, Thompson, T.J. State Specific Incident of Diabetes Among Adult, Participating States, 19951997 dan $2005 \quad-2007$. http://apps.nccd.cdc.gov/ddt_strs2 /nationaldiabetesprevalenceestima tes.aspx. Diunduh pada tanggal 13 Agustus 2012

Lindley,Benzel J.A. (2005). Self Care : A Clarification of Meaning and Examination of Supportive Strategies. Diabetes care, 23(7), 1646-1659

Lau, A.N., Tang, T., Halapy, H., Thorpe, K., Yu, C.H. (2012). Initiating Insulin in Patients with Type 2 Diabetes. Canadian Medical Association Journal,184(7),767-775.

Levich,Bridget. (2011). Diabetes management; optimizing roles for nurses in insulin initiation. Journal of Multidisiplinary Healthcare, 4,15-24.

McCarter R, Hempe \&Chalew (2005). Mean blood glucose an biological variation have greater influence on HbA1C levels than glucose instability an analysis off date from the diabetes control and complications trial.

McCloskey, J.C., Bulechek, G.M. (2006). Nursing Intervention Classification (NIC) $2^{\text {nd }}$ ed. St Louis: Mosby Years Book

Mahrova A., Svagrova K.(2013). Exercise Therapy - Additional tool for managing Physical and Psychological problems on hemodialysis.INTECH.chapter 36.753-821.

Nelson A.G., Kokkonen J., Arnall D.A.(2011). Twenty minutes of passive Strecting lowers glucose levels in an at risk population; an experimental study. Journal of physiotherapy. Vol.57.173-177.

Peyrot, M. Rubin, R.R, Lauritzen, T., Snoeks, F.J, Matthews, D.R, Skovlund, S.E. (2004). Psychosocial Problems and Barriers to Improved Diabetes Management : Result of The Cross-National Diabetes Attitudes, Wishes and Needs (DAWN) Study. Diabetes Medicine Insulin Therapy, 22(10), 1379-1452

Perkeni. (2011). Konsensus Pengelolaan dan Pencegahan 
Diabetes Mellitus Tipe 2 di Indonesia 2011. Jakarta

Pranoto,Agung. (2012). Insulin Daily Practice. Disampaikan dalam diabetes workshop VII. Surabaya Philips,Atone.(2007). Experiences of Patients with Type 2 Diabetes Starting Insulin Therapy. Nursing Standard, 21(3), 35-39.

Phillips, Atone. (2007). Starting patients on insulin therapy: Diabetes nurse specialist views. Nursing Standard, 21(30), 35-40. Polonsky,W.H., Fisher,L., Guzman,S., Caballero,L.V., Edelman. (2005). Psychological Insulin Resintance in Patients With Type 2 Diabetes. Diabates Care, 28(10), 2543-2548 Rubin, R.R., Peyrot, M., Kruger, D.F., Travis, L.B. (2009). Barriers to Insulin Injection Therapy : Patient and Health Care Provider Perspectives. The Diabetes Educator, 35(6), 1014-1036

Rufener,S.,Arunachalam, V., Ajluna, R., Sil, A. (2005). Thyroid Storm Precipitated by Infection : An Atypical Case Involving Multisystem Organ Dysfunction. Endocrinologist. 5, 111-114

Sarkar, P.D., Skaria, L.K., Agnihotram, G. (2013). Assesment of Nutritional Status in
Hyperthyroidism

Patients. NJIRM. 4(3).

Sanderson, Colina. (2009). Insulin Initiation : A Primary Care Perspective. Journal of Diabetes Nursing. 11 (9), 344-348

Shakibasadeh, $\quad$ E.,Larijani,B., Shojaeczadah,D., $\quad$ Rashidian,A., Forouzanter, M.H., Bartholomew,L.K. (2011).

Patient's Perpectives on Factors that Influence Diabetes Self Care. Iranian Journal Public Health. 40(4), 146-158

Sigal R.J., Kenny G.P., Wasserman D.H., Castaneda C. (2004). Physical Activity/exercise and Type 2 Diabetes. Journal diabetes care vol $27.2581-2539$

Smeltzer,S.C.,Bare,B.G. (2010). Brunner \& Suddarth's Textbook of Medical Surgical Nursing. Philadelpia : Lippincott

Soohyun, N. (2009). Factors Associated with Insulin Reluctane in Individuals with Type 2 Diabetes. Diabetes care, 33(8), 1747-1749

Soeatmadji, D.W. (2009). The 2 nd Thyroidology Update 2009. Indonesian Society of Endocrinology; Indonesian Study Group of Thyroidology; 
Indonesian Society of

Endocrinology Semarang Branch.

Semarang: Balai Penerbit

Universitas Diponegoro

Shaw, J.E., Sicree, R.A., Zimmet, P.Z. (2010)._Global estimates of the prevalence of diabetes for 2010 and 2030. Diabetes Research and Clinical Practice, 87 (1), 4-14

Tan, A.M., Muthusamy, L., Phoon, K.Y., Ow, J.H, Tan, N.C. (2011). Initiation of Insulin for Type 2 Diabetes Mellitus Patients; What are the Issues? A Qualitative Study. Singapore Medicine Journal, 52(11), 801-810

Then Z.C., Das S., Henry L.J. (2013).

Role of Exercise in the management of Diabetes mellitus: the global Scenario. Volume 8
Waspadji, S. 2009. Komplikasi Kronik DM: Mekanisme Terjadinya, Diagnosis dan Strategi Pengelolaan. Dalam: Buku Ajar Ilmu Penyakit Dalam, Jilid III. Balai Penerbit FKUI. Jakarta. Hlm. 1922-1929

Zhaolan, L., Ewen, L.N., Kim, C., Ettner, S.L., Herman, W.H., Karter, A.J.,Brown, A.F. (2010). Prevalence of Cronic Complications of Type 2 Diabetes Mellitus Outpatients- A Cross Sectional Hospital Based Survey in Urban China. Health and Quality of Life Outcomes, 8(1),6267. 